\title{
Study on the Electrochemical Anticorrosion Effect of Piezoelectric Materials in the Internal Environment of Water Supply Pipeline
}

\author{
T. Li*(**), G. Li*(**)†, X. Zhang***, S. Xu*(**) and H. Ghougassian*(**) \\ *School of Energy and Environmental Engineering, University of Science and Technology, Beijing, 100083, P. R. China \\ **Beijing Key Laboratory of Resource-oriented Treatment of Industrial Pollutants, Beijing, 100083, P. R China \\ ***Chinese Academy of Environmental Planning, Beijing, 100012, P. R. China \\ †Corresponding author: Ge Li; $1102868992 @ q q . c o m$
}

Nat. Env. \& Poll. Tech.

Website: www.neptjournal.com

Received: 08-08-2020

Revised: $20-09-2020$

Accepted: 01-11-2020

Key Words:

Piezoelectric material

Corrosion rate

Electrochemical anticorrosion

Pipeline anticorrosion

\begin{abstract}
The problem of corrosion in water supply pipelines not only poses a considerable threat to the safety of drinking water but also causes a large amount of water wastage due to the leakage of the pipeline network, which can be a chronic problem for a municipal water supply system, as observed in Beijing and other cities in China. In this study, a new piezoelectric PVDF fiber membrane was prepared by electrospinning process, and a piezoelectric anticorrosive film was fabricated based on the internal environment of the pipeline. In the simulated water supply pipeline environment, based on the principle of the piezoelectric effect and the principle of cathodic protection, the electrochemical corrosion protection effect of piezoelectric materials in the water supply pipeline environment, under different water quality conditions, was investigated by a single factor experiment. The results show that piezoelectric anticorrosion tablets have an obvious inhibitory effect on pipeline corrosion under different $\mathrm{pH}$ values, ammonium nitrate concentrations, chloride ion concentrations, and sulfate ion concentrations. Furthermore, under the conditions of $\mathrm{pH}$ neutral, alkaline, and high ion concentration, the piezoelectric anti-corrosion sheet can protect the pipeline by $100 \%$. Additionally, since the piezoelectric material can convert mechanical energy into electrical energy and does not cause pollution during the experiment, it has good environmental and economic benefits. The use of piezoelectric materials for preventing corrosion of pipelines is a frontier exploration. We believe that the improvement and development of material properties, and the combination of these new materials and traditional techniques, will provide new ideas and methods for pipeline anti-corrosion technology.
\end{abstract}

\section{INTRODUCTION}

With the continuous development of water treatment technology and process, the quality of pipeline feed water meets the standard. However, pipeline corrosion will cause significant degradation of the drinking water quality through the intrusion of pollutants into the pipes, which will have an impact on human health, and bring massive economic losses. Therefore, there is a need to explore new high-efficiency, energy-saving, and environmentally friendly solutions. Pipeline corrosion is a very complicated process with various influencing factors. In addition to the physical conditions of the pipe itself, the characteristics of the water in the pipe are also the main contributing factor to pipe corrosion. This includes $\mathrm{pH}$, alkalinity, hardness, dissolved oxygen, chloride ion, sulfate, nitrate, temperature, bacterial community, etc. (Hu et al. 2018, McNeill \& Edwards 2002, Sarin et al. 2004, Slaimana \& Hasan 2010, Sun et al. 2014, Wang \& Ma 2009, Zhang et al. 2018). At present, pipeline anti-corrosion technology generally includes pipe lining technology ( $\mathrm{Li}$ et al. 2016), pipe coating technology (Zhu et al. 2018), and cathodic protection technology (Loto et al. 2019). To solve the problems of high cost, poor performance, and secondary pollution in these methods, this paper combines piezoelectric materials with anti-corrosion technology to achieve energy conservation and an environmentally sound approach.

In recent years, the development and usage of piezoelectric materials have witnessed a widespread resurgence. Piezoelectric materials were widely used during the First World War, and at that time, quartz was used as a resonator for the ultrasonic source in SONAR, and submarine detection was achieved by echolocation (Dineva et al. 2014). Piezoelectric materials are currently used in high-tech fields, such as information technology, laser technology, navigation technology, and biology (Duan \& Xing 2015), a wide range of applications in transducer technology (Joseph et al. 2018, Kim et al. 2011), sensors (Wang \& Chen 2016), filters (Li 2009), etc. Piezoelectric catalytic technology applied to environmental restoration in recent years is also closely related to piezoelectric materials (Zhang et al. 2019), and their piezoelectric effect and sensing effect can be used to apply them in a wider range of fields 
(Butt et al. 2016, Chen et al. 2019, Ramatlo et al. 2018, Tang et al. 2019, Xu et al. 2018).

Based on the vibration mechanism of piezoelectric materials and the corrosion mechanism of pipes, the principle of piezoelectric materials and electrochemical corrosion protection is applied in pipeline anti-corrosion technology. This paper explores whether the continuously provided electrons by the piezoelectric material can inhibit corrosion and protect the pipeline under different conditions. Not only is this an attempt in the application of new materials, but it is rather a new way of thinking in pipeline anti-corrosion technology, which will further promote the development of electrochemical anti-corrosion technology.

\section{MATERIALS AND METHODS}

\section{Piezoelectric Anticorrosive Sheet Making Process}

The manufacturing process of the piezoelectric anticorrosive sheet is divided into two steps: preparation of the electrospun fiber membrane, and preparation of the electrospun piezoelectric anticorrosive sheet.

Preparation of electrospun fiber membrane: The electrospinning nanofibers were received by a dual-motor-controlled, rotatable, and reciprocating cylinder receiving device. First, a certain amount of PVDF powder was weighed and mixed in a DMF/acetone (60:40) mixed solvent. The doping amount of $\mathrm{FeCl}_{3} \cdot 6 \mathrm{H}_{2} \mathrm{O}$ was $50 \mu \mathrm{mol} . \mathrm{g}^{-1} \mathrm{PVDF}$, thereby obtaining a PVDF spinning solution having a PVDF concentration of $10 \%$. Then, an appropriate amount of PVDF spinning solution was transferred to a syringe, and the syringe was placed on the syringe pump. The positive electrode of the high-voltage DC power source was connected to the needle, and the negative electrode was connected to the receiving roller. The piezoelectric material was prepared under the conditions of a spinning voltage of $16 \mathrm{kV}$, a spinning speed of $1.0 \mathrm{~mL} \cdot \mathrm{h}^{-1}$, and a spinning distance of $15 \mathrm{~cm}$ (Ribeiro et al. 2010, Zhao et al. 2005). When the amount of spinning solution reached $2 \mathrm{~mL}$, the high-voltage DC power supply and the syringe pump were turned off, and the aluminum plate was carefully removed. The sample was marked, placed in an oven, dried at $50^{\circ} \mathrm{C}$ for 30 minutes, and stored for later use. The electrospinning process was carried out at room temperature and relative humidity of $40 \%$ to $50 \%$. Fig. 1 represents an SEM image of an electrospun piezoelectric material. The electrospun fiber had a relatively flat surface, a clear shape, a uniform texture, and a relatively uniform fiber diameter distribution.

Preparation of Electrospun Piezoelectric Anticorrosive Sheet: The PVDF piezoelectric material thus produced was subjected to four processes of film cutting, edge treatment,

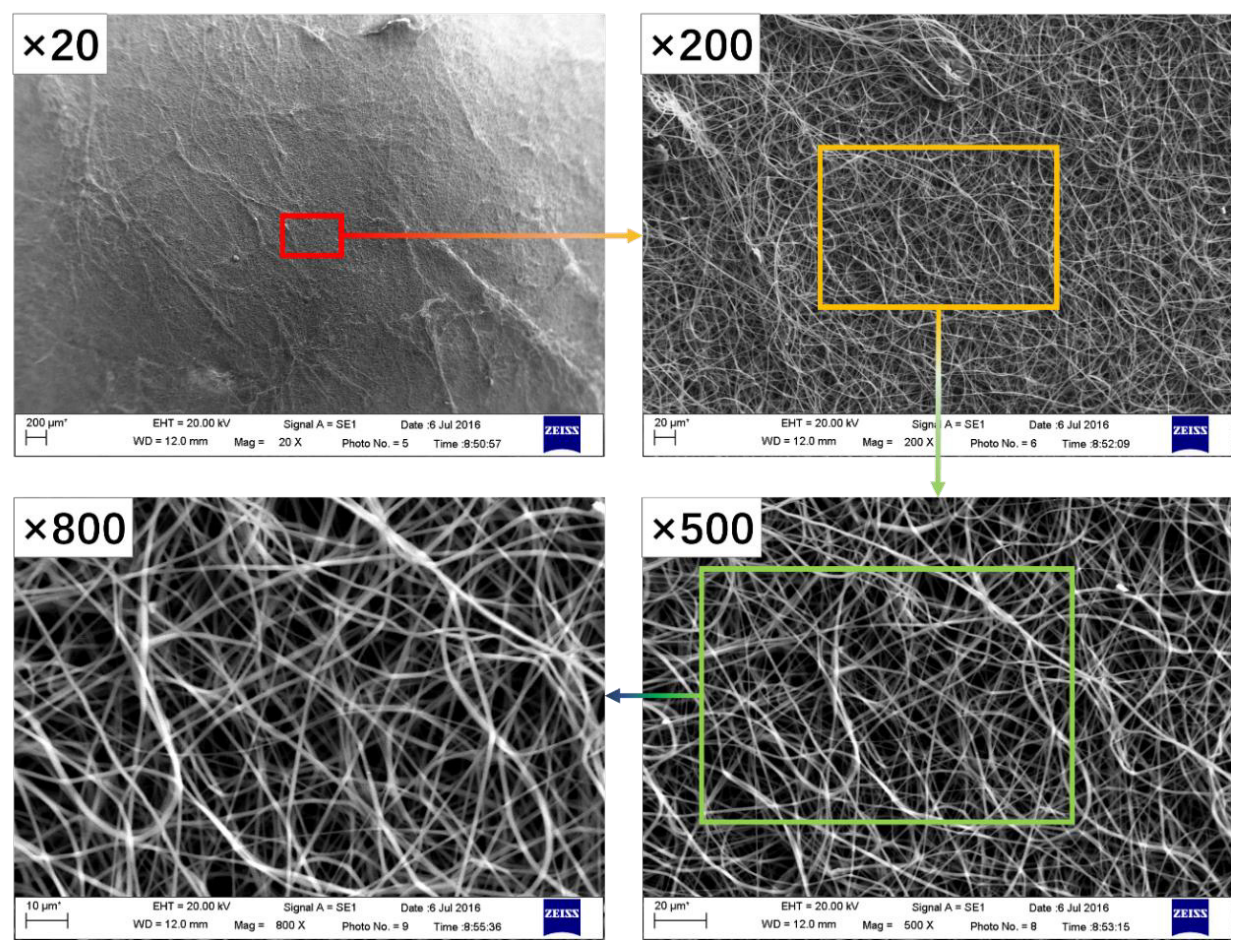

Fig. 1: SEM image of electrospun piezoelectric material. 
electrode extraction, and adding of a protective layer to prepare a piezoelectric anticorrosive sheet for experiments (Fig. 2).

Film cutting: An area of the prepared electrospun PVDF fiber membrane, slightly larger than the required area, was marked and then cut with sharp scissors, and its edge was marked. In this paper, the fiber membrane is cut to a size of $2.0 \mathrm{~cm} \times 2.0 \mathrm{~cm}$.

Edge treatment: The edges of the cut fiber film were covered with a layer of insulating tape to prevent the upper and lower copper foil electrodes from short-circuiting due to collision. This also had a certain protective effect on the fiber film in use.

Electrode extraction: The conductive copper foil tape was cut to the desired shape and then carefully attached to the cut fiber membrane. The conductive copper foil tape acts as an electrode, which improves the operability of the preparation process, and makes the preparation process simple and convenient.

Adding of protective layer: Since the conductive copper foil electrode was directly attached to both sides of the fiber membrane, it was exposed to the outer environment and could have easily been damaged during use, affecting the experimental process. Therefore, it was necessary to add a protective layer on the outside and use insulating tape as a protective layer, which served both as protection and insulation.

\section{Anti-Corrosion Experiment Process}

First, to ensure the same corrosion area of cast iron during the experiment, a $1 \mathrm{~cm} \times 2 \mathrm{~cm}$ corrosion zone was reserved on the cast iron sheet, and other parts were covered with silicone rubber to isolate the corrosion solution. The height of the corrosive solution was controlled slightly above the corrosion zone and was in contact with the silicone rubber sheet, thus ensuring that all the corrosion zones of the cast-iron sheets were corroded and the corrosion area was consistent throughout the experiment.

Second, this study simulated cast iron corrosion in a beaker environment. In practice, only piezoelectric sheets are built into pipes in this method, not the entire device is put into pipes. The piezoelectric power generation device in Fig. 3 was composed of a vibration experiment platform (ESS-050-120 DongLing Technologies), a piezoelectric sheet, a signal generator, and an oscilloscope. The vibration experiment platform was controlled by a signal generator to provide cyclic bending-releasing external force. Then an external force was applied to the piezoelectric sheet to make the piezoelectric sheet generate electrical energy. At this

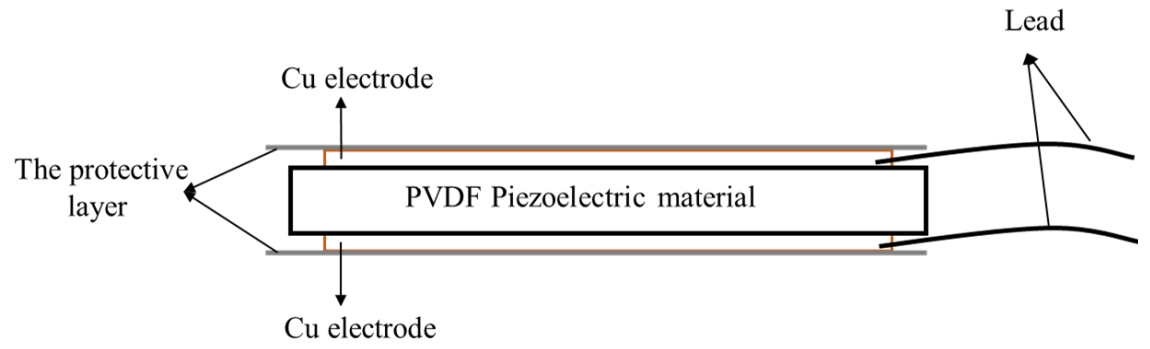

Fig. 2: Schematic diagram of electrospun piezoelectric anti-corrosion sheet.

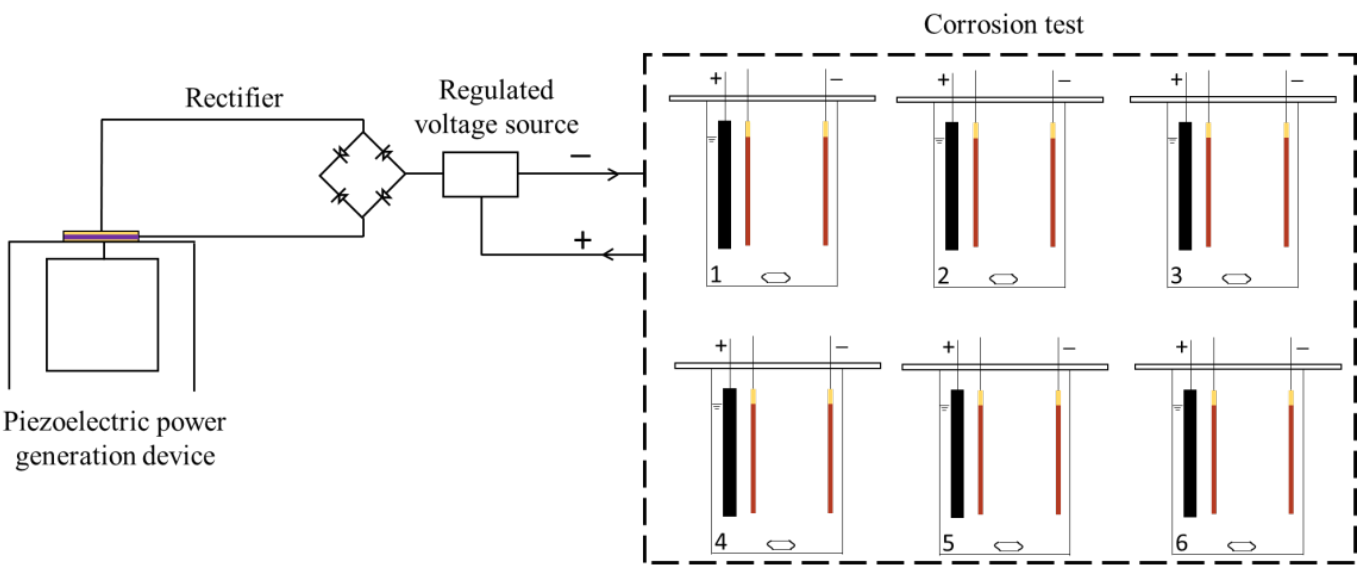

Fig. 3: Piezoelectric anticorrosion device schematic. 
time, the current generated by the piezoelectric sheet was an alternating current, so the alternating current was changed to direct current through a rectifier to meet the basic conditions of cathodic protection. Then the regulated voltage source was passed to keep the current stable. Finally, the protection current generated by the piezoelectric sheet was externally connected to the cast iron sheet to be protected, and the cast iron corrosion test was conducted. As shown in Fig. 3, in the 6 beakers of the corrosion test apparatus, different solutions were placed according to the experiment, and two cast-iron sheets with silicone rubber were placed in a beaker containing a specific solution, and the rotor speed was adjusted to simulate the water flow rate. The anti-corrosion effect of the piezoelectric anticorrosive sheet was analyzed by comparing the corrosion changes of the cast iron with or without the piezoelectric protection device. The black bars in the beaker are anodes which are carbon rods.

Through reference to various literature studies, and based on the characteristics of environmental conditions in closed water pipes, experiments were carried out using four corrosion factors: $\mathrm{pH}$, ammonium nitrate, sodium chloride, and sodium sulfate. Hydrogen ions participate in the cathodic reaction of iron corrosion. The $\mathrm{pH}$ is related to the solubility and form of the iron compound in the scale. And the change in $\mathrm{pH}$ also affects the formation of various oxides and hydroxides of iron. This in turn affects the corrosion rate of iron and the release of iron. In an acidic solution, nitrate reacts with zero-valent iron to form an ammonium-contaminated water body (Zhang \& Edwards 2007), and ammonium causes rapid consumption of dissolved oxygen; for most bacteria, ammonium is a better source of nitrogen relative to nitrate, which can cause microbial growth and iron corrosion. Chloride and sulfate ions interfere with the formation of calcium and iron protective layers and can replace the hydrogen bonds in the passivation layer metal ions, thereby destroying the passivation film and chemically reacting with the scale to form dissolved ferrous ions. The passivation layer attached to the pipe scale layer is replaced by rust, which accelerates the corrosion rate of the pipe and increases the release of iron from the pipe network (Hu et al. 2018). Sulfate ions also participate in microbial reactions in the pipe network (Yang et al. 2014). Moreover, $\mathrm{pH}$ value, nitrate concentration, chloride ion concentration, and sulfate concentration are the typical influencing factors in the current corrosion process of cast iron. Therefore, the four influencing factors were selected as the optimization conditions for this study.

Deionized water was added to a $250 \mathrm{~mL}$ beaker to adjust the $\mathrm{pH}$ or to add different concentrations of the solution (see Table 1 for details) to obtain a $200 \mathrm{~mL}$ sample solution for the single factor impact test. In the experiment, other influencing factors were strictly controlled. In the experiment of
pH influencing factors, $\mathrm{NH}_{4} \mathrm{NO}_{3}, \mathrm{NaCl}$, and $\mathrm{Na}_{2} \mathrm{SO}_{4}$ were not added to the solution. When the $\mathrm{NH}_{4} \mathrm{NO}_{3}, \mathrm{NaCl}$, or $\mathrm{Na}_{2} \mathrm{SO}_{4}$ concentration analysis experiment was carried out, the $\mathrm{pH}$ was controlled at around 7. For each of the $\mathrm{NH}_{4} \mathrm{NO}_{3}, \mathrm{NaCl}$, and $\mathrm{Na}_{2} \mathrm{SO}_{4}$ solutions that were prepared, none of the other two compounds were added to the solution. For instance, the $\mathrm{NH}_{4} \mathrm{NO}_{3}$ solutions did not contain any $\mathrm{NaCl}$ or $\mathrm{Na}_{2} \mathrm{SO}_{4}$. The iron sheets were weighed daily to ensure accurate measurement of changes on each day. Three parallel experiments were performed.

Table 1: Details of the solution under different conditions (Room temperai ture $20^{\circ} \mathrm{C} \sim 25^{\circ} \mathrm{C}$ ).

\begin{tabular}{|ll|}
\hline Influence condition & Details \\
\hline $\mathrm{pH}$ & $3,5,7,8,9,11$ \\
$\mathrm{NH}_{4} \mathrm{NO}_{3}$ concentration $\left(\mathrm{mg} . \mathrm{L}^{-1}\right)$ & $0,100,200,250,500,1000$ \\
$\mathrm{NaCl}$ concentration $\left(\mathrm{mg} . \mathrm{L}^{-1}\right)$ & $0,100,200,250,500,1000$ \\
$\mathrm{Na}_{2} \mathrm{SO}_{4}$ concentration $\left(\mathrm{mg} . \mathrm{L}^{-1}\right)$ & $0,100,200,250,500,1000$ \\
\hline
\end{tabular}

\section{Analytical Methods}

The $\mathrm{pH}$ of the solution was measured using a $\mathrm{pH}$ meter (Mettler-Toledo 320). The weight-loss method was adopted. That is, the mass change of the cast iron sheet before and after the experiment is weighed to judge the corrosion rate of the cast iron and the protective effect of the piezoelectric anticorrosive sheet. The corrosion products on the cast-iron sheets were cleaned with deionized water, then the cast iron sheets were placed in an oven, dried at $50^{\circ} \mathrm{C}$ for 5 hours, then weighed and recorded (Yang et al. 2018). The voltage and current values in the environmental system during the whole experimental period were recorded by the voltage and current collector. The power consumption is obtained by voltage value and current value and is used to analyze the protection of cast iron in a corrosive environment under different power consumption conditions. The corrosion morphology of the cast iron was obtained by operating an electron scanning microscope (SEM (LEO-1450 Carl Zeiss) at $20.00 \mathrm{kV}$. The surface area of the SEM image was analyzed using Image-Pro Plus software.

\section{RESULTS AND DISCUSSION}

\section{Effect of Initial pH}

The initial $\mathrm{pH}$ of the solution has an important impact on the corrosion protection of the pipeline. This experiment explored the corrosion of cast iron with and without current protection at different $\mathrm{pH}$.

Fig. 4 shows that the average rate of corrosion of cast iron decreases with increasing $\mathrm{pH}$. The corrosion rate is relatively small and the difference is minimal when the $\mathrm{pH}$ 
is neutral and alkaline and is lower than the daily average rate. In the acidic environment with $\mathrm{pH}=3$, the corrosion rate is the highest on the first day, reaching $278 \mathrm{~g} .\left(\mathrm{m}^{-2} \cdot \mathrm{d}^{-1}\right)$, and finally stabilized at around $146 \mathrm{~g} .\left(\mathrm{m}^{-2} \cdot \mathrm{d}^{-1}\right)$. On the seventh day, the corrosion rate of the $\mathrm{pH}=3$ solution is 122.9 g. $\left(\mathrm{m}^{-2} \cdot \mathrm{d}^{-1}\right)$ higher than that of the $\mathrm{pH}=7$ solution $(22.9$ g. $\left(\mathrm{m}^{-2} \cdot \mathrm{d}^{-1}\right)$, which is mainly due to the hydrogen evolution corrosion of cast iron in an acidic environment. This is consistent with the study of Yang et al. (2017). The average corrosion rate of the cast iron sheet is sharply reduced with the protection device when compared with the corrosion rate without the protection device. In comparison, the corrosion rate drops to zero in neutral and alkaline solutions. In the acidic environment with $\mathrm{pH}=3$ and $\mathrm{pH}=5$, the corrosion rate is zero in the first four days, and slight corrosion occurs in the last two days. The highest corrosion rate is 7.08 g. $\left(\mathrm{m}^{-2} \cdot \mathrm{d}^{-1}\right)$. The protection current makes the cast iron in a state of excessive electrons so that the electron migration of metal corrosion is suppressed, and the occurrence of corrosion is avoided or reduced (Meng \& Wang 2016).

As shown in Fig. 5, with the presence of the protection device's current, the protection degree in all solution systems is above $90 \%$. Among them, in a neutral and alkaline environment, the protection degree can reach $100 \%$ for all seven days; however, it can reach $100 \%$ only in the first 4 days at $\mathrm{pH}=3$ and $\mathrm{pH}=5$. The cast iron without a protective device has obvious corrosion: the surface has rust and corrosion pit, and in contrast, the surface of the cast iron with protection device has no rust, is smooth, and less corroded, which indicates that the external protection device plays a good anti-corrosion role. Regarding power consumption, in different $\mathrm{pH}$ set-ups, the average daily electricity consumption gradually eases with time. The lowest power consumption $(709.73 \mathrm{~mW} \bullet \mathrm{h})$

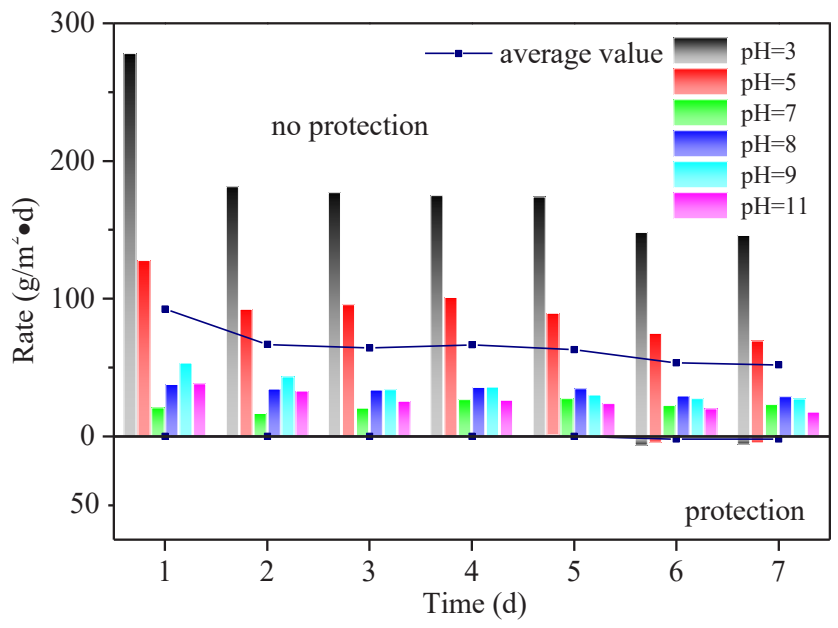

Fig. 4: Average rate change of cast iron under different $\mathrm{pH}$ conditions.

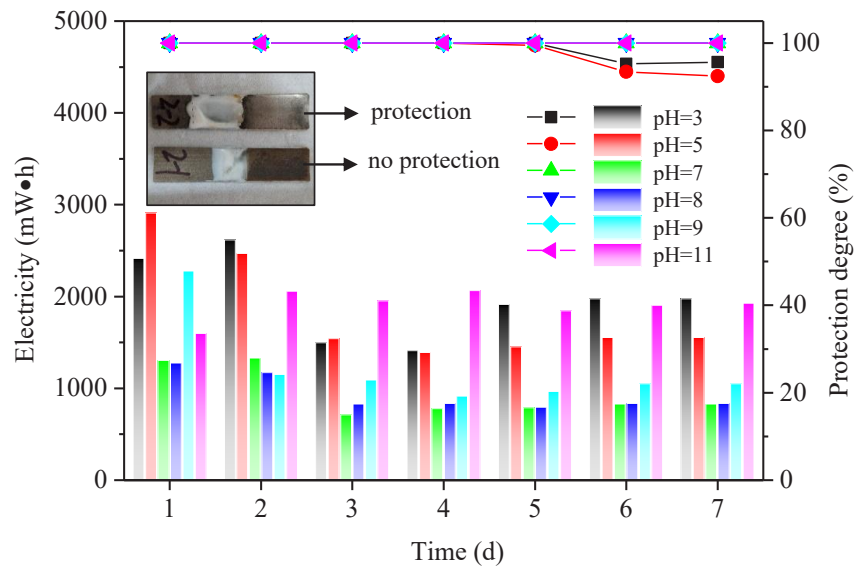

Fig. 5: Under the protection device, the changes in protection degree and power consumption of cast iron under different $\mathrm{pH}$ conditions. 
at $\mathrm{pH} 7$ is compared with the acidic conditions of the same time period, and the power consumption is shown to be reduced by about $50 \%$.

\section{Effect of Ammonium Nitrate Concentration}

Nitrate ions have a great influence on the corrosion of cast iron. This experiment explored the corrosion of cast iron with and without current protection at different ammonium nitrate concentrations.

As shown in Fig. 6, in the ammonium nitrate solution eni vironment system, the average corrosion rate increases with the increase of experiment time in the 5-day corrosion cycle. However, the corrosion rate of cast iron does not change regularly with the increase of nitrate ion concentration. Except for the $0 \mathrm{mg} . \mathrm{L}^{-1}$ solution, the corrosion rate was the lowest for the $500 \mathrm{mg} . \mathrm{L}^{-1}$ solution, which was $47.7 \mathrm{~g} .\left(\mathrm{m}^{-2} \cdot \mathrm{d}^{-1}\right)$. The corrosion rate was the highest for the $1000 \mathrm{mg} . \mathrm{L}^{-1}$ and 100 $\mathrm{mg} . \mathrm{L}^{-1}$ solutions, which exceeded the average, and reached their maximum levels on the fifth day: $59.3 \mathrm{~g} \cdot\left(\mathrm{m}^{-2} \cdot \mathrm{d}^{-1}\right)$ and $54.8 \mathrm{~g} .\left(\mathrm{m}^{-2} \cdot \mathrm{d}^{-1}\right)$ respectively. When the protective current is applied, the average corrosion rate of the cast iron is greatly controlled in the ammonium nitrate solution system, and the corrosion rate is reduced to zero. In the deionized water environment, where there is poor electrical conductivity, the protection current is small and the corrosion is not effectively controlled.

From Fig. 7, the corrosion of cast iron is well controlled with the addition of the protective device, and the protection of cast iron is $100 \%$ except for the solution without ammonium nitrate. In the ammonium nitrate solution systems, the amount of electricity consumption is proportional to the concentration of the solution (except $0 \mathrm{mg} . \mathrm{L}^{-1}$ ). Therefore, without protection, the solution has a minimum corrosion rate comparable to that of about $500 \mathrm{mg} . \mathrm{L}^{-1}$. In the case of protection, combined with the corrosion rate and power consumption, the concentration of the solution is controlled at about $200 \mathrm{mg} . \mathrm{L}^{-1}$. Its power consumption is reduced by $55 \%$ to $85 \%$ when compared to $500 \mathrm{mg} . \mathrm{L}^{-1}$ and $1000 \mathrm{mg}$. $\mathrm{L}^{-}$ ${ }^{1}$, respectively. The minimum power consumption is 924.41 $\mathrm{mW} \cdot \mathrm{h}$, although the power consumption is about $50 \%$ higher than that of $100 \mathrm{mg} . \mathrm{L}^{-1}$. However, since the corrosion rate on the fourth day is about $18 \%$ lower than that of the $100 \mathrm{mg} . \mathrm{L}^{-1}$ solution, controlling the solution concentration to $200 \mathrm{mg} . \mathrm{L}^{-}$ ${ }^{1}$ can completely protect the cast iron and save electricity.

\section{Effect of Sodium Chloride Concentration}

The chloride ion concentration has a large effect on the corrosion of cast iron. This experiment explored the corrosion of cast iron with or without current protection at different chloride ion concentrations.

From Fig. 8, in the chloride ion environment system, the average corrosion rate decreases gradually with the experg iment time, and the higher the concentration, the faster the corrosion rate, indicating that the increase of $\mathrm{Cl}^{-}$concentration will accelerate the release of iron and promote the corrosion of cast iron (Hu et al. 2018). This can be observed at chloride concentrations of $0 \mathrm{mg} . \mathrm{L}^{-1}$ and $100 \mathrm{mg} . \mathrm{L}^{-1}$, where the average rate of corrosion of cast iron is always below

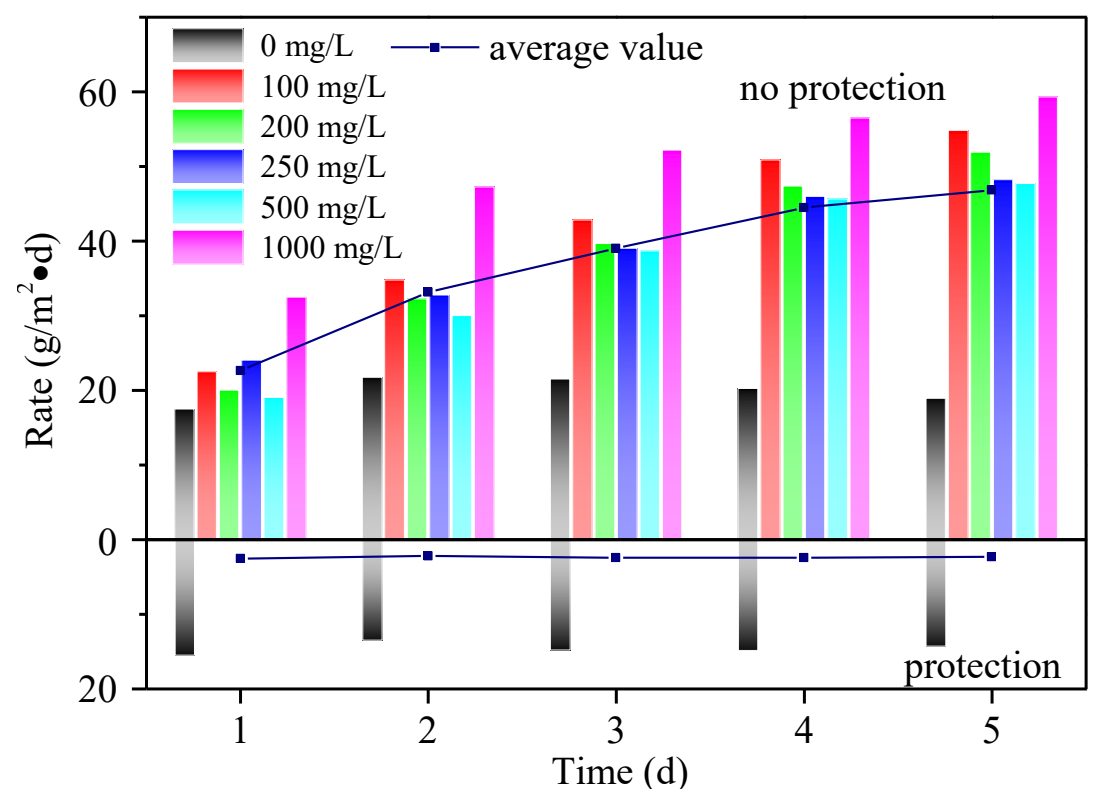

Fig. 6: Average rate change of cast iron under different ammonium nitrate concentrations. 


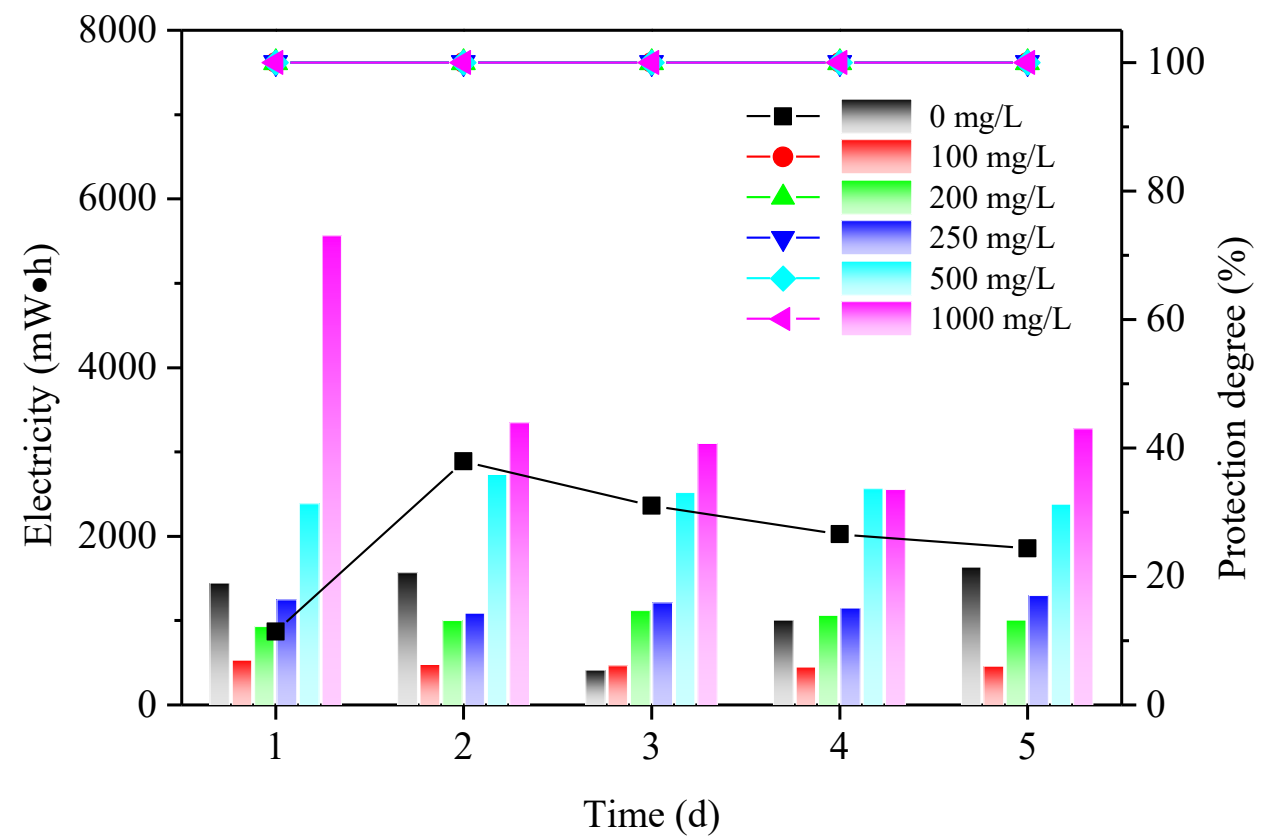

Fig. 7: Under the protection device, the changes in protection degree and power consumption of cast iron under different ammonium nitrate concentrations.

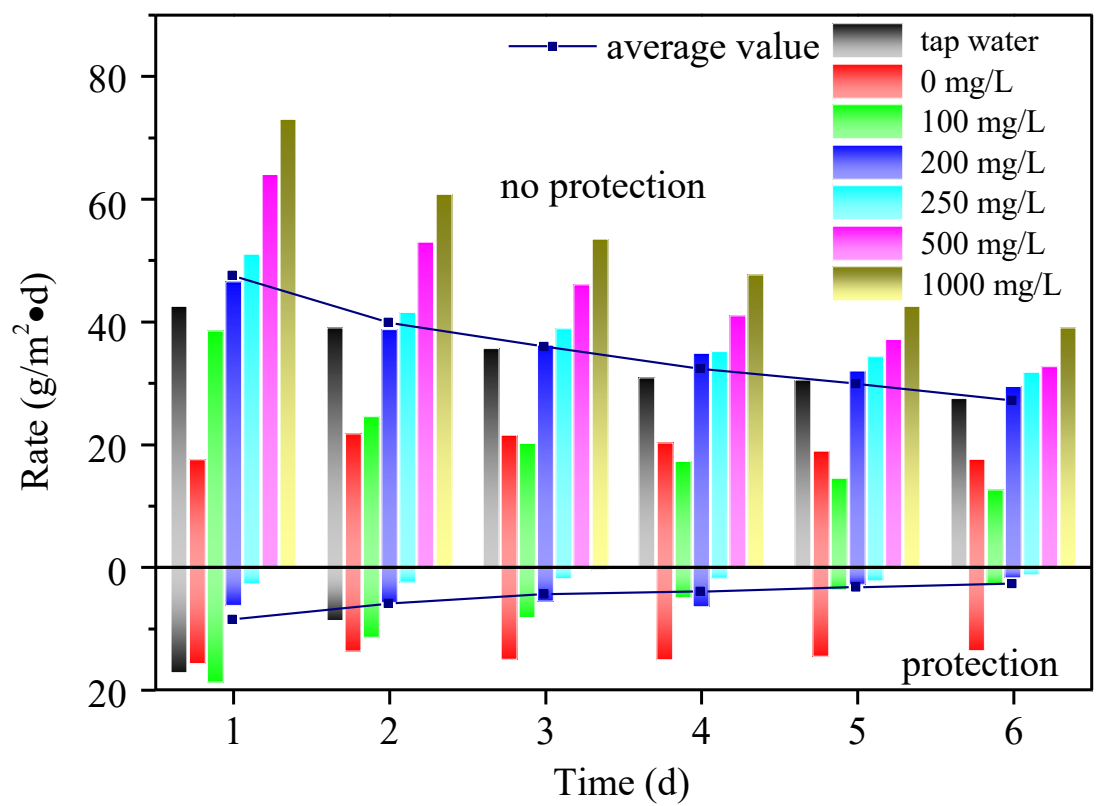

Fig. 8: Average rate change of cast iron under different chloride ion concentrations.

the overall average. Due to the presence of ionic substances in tap water, the corrosion rate of tap water is between the corrosion rates observed for the $100 \mathrm{mg} . \mathrm{L}^{-1}$ and $200 \mathrm{mg} . \mathrm{L}^{-1}$ solutions of sodium chloride. There is no ionic substance in the deionized water, and the corrosion rate is relatively low. We observe it first increasing, then falling, and then gradual. When the current is applied, the average corrosion rate of cast iron in the sodium chloride solution system is greatly reduced, especially for the solutions of $1000 \mathrm{mg} . \mathrm{L}^{-1}$ and $500 \mathrm{mg} . \mathrm{L}^{-1}$, where the corrosion rate is almost zero. This is because the solution concentration is high and the protection current is large, so the average corrosion rate is very low, and the overall corrosion rate tends to decrease. When the current is applied, the average corrosion rate of cast iron in 
tap water was higher than the corrosion rate of cast iron in high-concentration solutions. The maximum value of the average corrosion rate of cast iron in tap water reached 17 g. $\left(\mathrm{m}^{-2} \cdot \mathrm{d}^{-1}\right)$, while the maximum value in high-concentration solutions was $0.33 \mathrm{~g} .\left(\mathrm{m}^{-2} \cdot \mathrm{d}^{-1}\right)$. However, due to the poor conductivity of deionized water, the corrosion rate in deionized water $\left(0 \mathrm{mg} . \mathrm{L}^{-1}\right)$ is not significantly reduced, and the cathodic protection is not obvious.

As shown in Fig. 9, under tap water conditions, the dee gree of protection of the protected cast iron in the first two days was not ideal, the degree of protection was $60 \%$ and $78.2 \%$ respectively. While in a sodium chloride solution system with a protective current applied, the cast iron is well protected, especially at high concentrations (1000 mg.L. $\mathrm{L}^{-1}$, $500 \mathrm{mg} . \mathrm{L}^{-1}$ ). When the conductivity of the solution increases, the protection current also increases, and the degree of protection is over $99.3 \%$. Therefore, from the perspective of the corrosion rate and degree of protection of cast iron, piezoelectric materials are more suitable for corrosion protection of cast iron in high-concentration solutions. Meanwhile, the daily electricity consumption is relatively stable. The power consumption is roughly positively correlated with the concentration of the solution. The corrosion rate of cast iron is also positively correlated with the solution concentration. Given that the protection degree can reach $100 \%$ at high concentrations, the cathodic protection effect is obvious. Therefore, from the perspective of anti-corrosion, it is advisable to try to control the lower concentration of sodium chloride without using a protection device. In the case of protection, the sodium chloride concentration is controlled at about $500 \mathrm{mg} . \mathrm{L}^{-1}$, and the power consumption is $25 \%$ to $50 \%$ lower than that of the $1000 \mathrm{mg} . \mathrm{L}^{-1}$ solution, while the minimum power consumption is $2301.41 \mathrm{~mW} \cdot \mathrm{h}$. This means that the system can save electricity and achieve a good anti-corrosion effect.

By visually comparing Fig. 10 (a d) and (e h) and using Image-Pro Plus software to analyze the SEM images, the proportion of the corrosion area can be obtained, defined as the degree of corrosion (Table 2). It can be seen from Fig. 10 that at $500 \mathrm{mg} . \mathrm{L}^{-1}$ without protection, the corrosion morphology is very detailed. So the scale was positioned to $10 \mu \mathrm{m}$. According to the actual situation at that time, the magnification was appropriately increased to better show the appearance of cast iron corrosion. Whether in the tap water solution or the sodium chloride solution, the corrosion of the cast iron without the protective device is serious, and the surface has obvious dense corrosion pits, and the products of corrosion can be clearly seen after the magnification. The corrosion degree of cast iron in tap water is $37.04 \%$, the diameter of the corrosion pit is about $140 \mu \mathrm{m}$, and the corrosion degree of cast iron in sodium chloride solution is $50.72 \%$. After the protection device is added, although certain corrosion occurs, the corrosion degree of cast iron in the tap water is $19.70 \%$, and the corrosion degree of the cast iron in the sodium chloride solution is $22.86 \%$. The corrosion condition is greatly improved compared to the results obtained

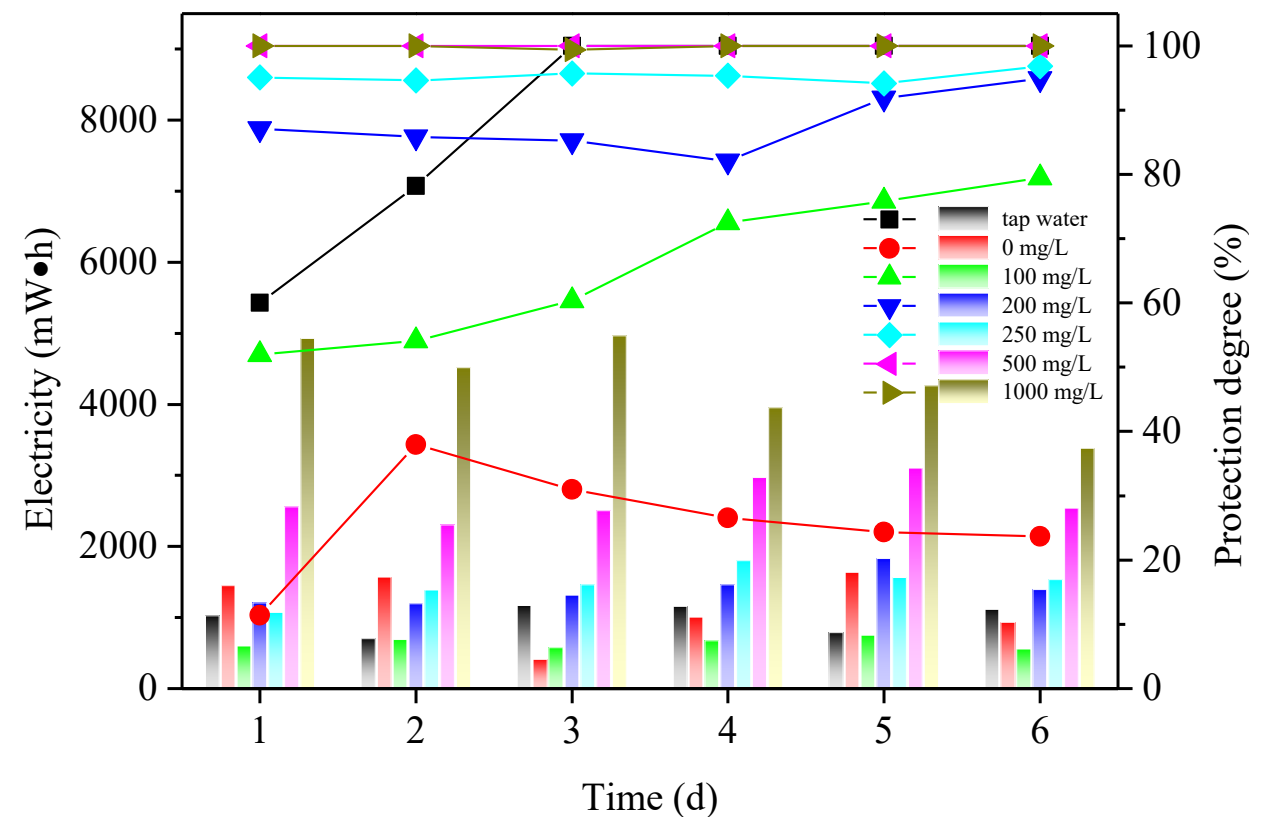

Fig. 9: Under the protection device, the changes in protection degree and power consumption of cast iron under different sodium chloride concentrations. 

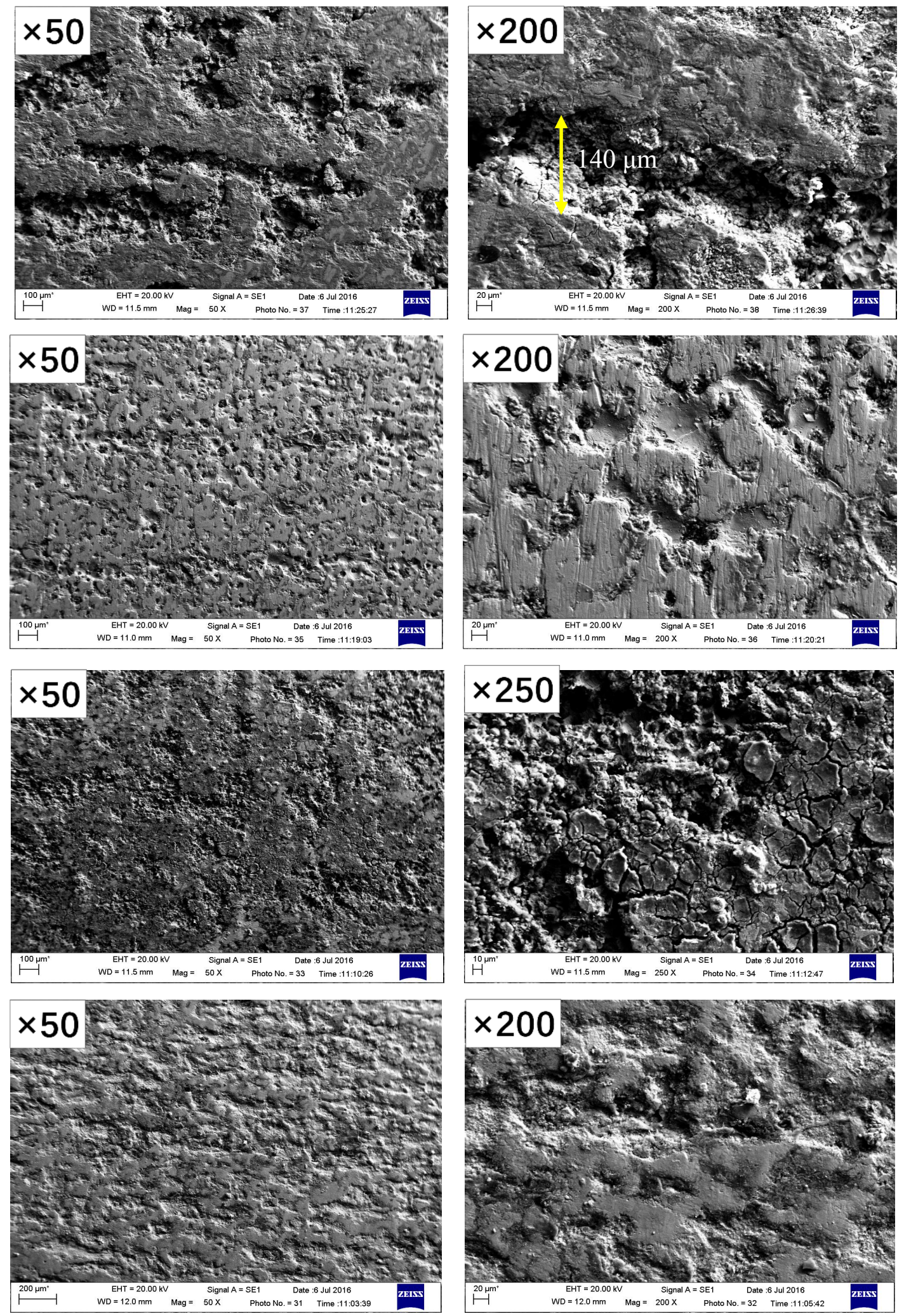

Fig. 10: SEM image of cast iron in different concentrations of sodium chloride solution, at 50, 200, or 250 times magnification. 
Table 2: Cast iron corrosion degree table (data from images at 50 times magnification).

\begin{tabular}{|lllll|}
\hline Solution condition & $\begin{array}{l}\text { Tap water } \\
\text { no protection }\end{array}$ & $\begin{array}{l}\text { Tap water } \\
\text { protection }\end{array}$ & $\begin{array}{l}500 \mathrm{mg} . \mathrm{L}^{-1} \\
\text { no protection }\end{array}$ & $\begin{array}{l}500 \mathrm{mg} . \mathrm{L}^{-1} \\
\text { protection }\end{array}$ \\
\hline Corrosion degree $(\%)$ & 37.04 & 19.70 & 50.72 & 22.86 \\
\hline
\end{tabular}

without the use of the protection device. This shows that the protection device greatly improves the corrosion protection of cast iron. Without the protection device, the corrosion of cast iron in $500 \mathrm{mg} . \mathrm{L}^{-1}$, sodium chloride solution is very high, the corrosion pit is dense, and the surface is very rough. Its corrosion degree to cast iron $(50.72 \%)$ is stronger than that of tap water (37.04\%), which corresponds to the conclusion of Fig. 8.

\section{Effect of Sodium Sulfate Concentration}

This experiment also explored the effect of sulfate ions on the corrosion of cast iron.

From Fig. 11, in the experimental sodium sulfate ent vironment systems, the average corrosion rate is below 80 g. $\left(\mathrm{m}^{2} \bullet \mathrm{d}\right)$. The corrosion rate drops first and then increases in the solution of $200 \mathrm{mg} . \mathrm{L}^{-1}$ concentration of sodium sulfate. At other concentrations, the corrosion rate increases first, then decreases and then increases again. When the concentration of sodium sulfate is $0 \mathrm{mg} . \mathrm{L}^{-1}$, the average rate of corrosion of cast iron is lower than the average value. At a concentration of $100 \mathrm{mg} . \mathrm{L}^{-1}$, the average rate on the third day and after is below the average. Among all tested concentrations, cast iron has the fastest corrosion rate in a $500 \mathrm{mg} . \mathrm{L}^{-1}$ solution.
This indicates that the increase of SO2- 4 concentration will accelerate the release of iron and promote the corrosion of cast iron (Hu et al. 2018, Yang et al. 2014). Comparingly, after the current is applied, the average corrosion rate of cast iron is greatly controlled in the sodium sulfate environment systems. Deionized water poses an exception, since the electrical conductivity is poor and the protection current is small, the corrosion rate is still large after the current is applied. The cast iron in other concentrations did not corrode in the first four days, while it was slightly corroded at $100 \mathrm{mg} . \mathrm{L}^{-1}$ and $500 \mathrm{mg} . \mathrm{L}^{-1}$ after four days, and the maximum rate on the sixth day was $1 \mathrm{~g} .\left(\mathrm{m}^{-2} \cdot \mathrm{d}^{-1}\right)$ and $7.9 \mathrm{~g} .\left(\mathrm{m}^{-2} \cdot \mathrm{d}^{-1}\right)$, respectively.

From Fig. 12, cast iron is well protected in a sodium suli fate solution with a protective current. For the concentrations of $200 \mathrm{mg} . \mathrm{L}^{-1}, 250 \mathrm{mg} . \mathrm{L}^{-1}$, and $1000 \mathrm{mg} . \mathrm{L}^{-1}$ solution, the protection can reach $100 \%$. In the solutions with concentrations of $500 \mathrm{mg} . \mathrm{L}^{-1}$ and $100 \mathrm{mg} . \mathrm{L}^{-1}$, some corrosion began to appear after the 4th and 5th days, however, the degree of protection was still above $88.4 \%$. In the deionized water system, the degree of protection is poor. The power consumption decreases first and then increase with the experiment time. The $200 \mathrm{mg} . \mathrm{L}^{-1}$ and $250 \mathrm{mg} . \mathrm{L}^{-1}$ solutions consume a large amount of electricity, while the $1000 \mathrm{mg} . \mathrm{L}^{-1}$ solution

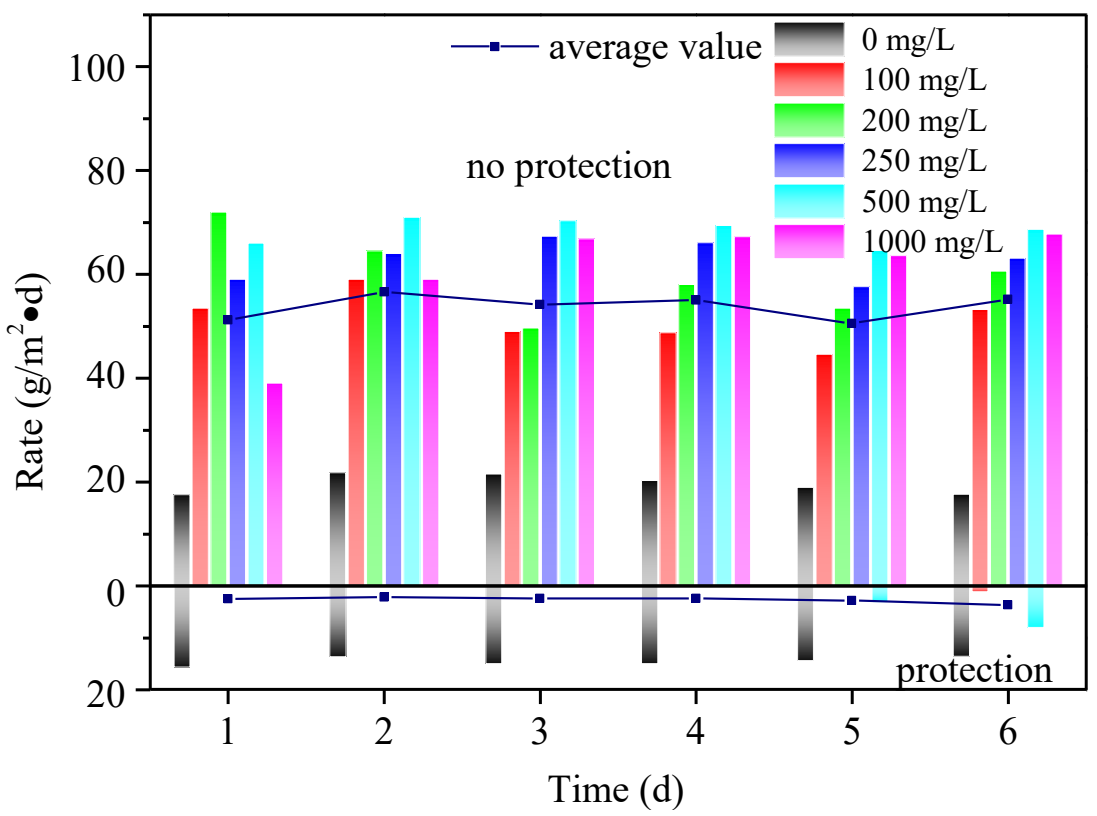

Fig. 11: Average rate change of cast iron under different sulfate ion concentrations. 
consumes less power $(390.70 \mathrm{~mW} \cdot \mathrm{h})$, which is $5 \%$ to $90 \%$ lower than the other two solutions. The cast-iron protection of these three solution systems can reach $100 \%$. Therefore, it is advisable to control the solution at a low concentration of about $100 \mathrm{mg} . \mathrm{L}^{-1}$ without protection. In the case of protection, the solution concentration should be controlled at about $1000 \mathrm{mg} \cdot \mathrm{L}^{-1}$.

By visually comparing Fig. 13 (a-d), and using Image-Pro Plus software to analyze the SEM image, the proportion of corrosion area is obtained, which is the corrosion degree (Table 3). Being under the protection of the device and being unprotected by the device have little effect on the corrosion of cast iron in deionized water, where the corrosion degree is between $60 \%$ and $70 \%$. This is mainly due to the conductivity of deionized water being poor and not meeting the needs of cathodic protection. Comparing Fig. $13(\mathrm{e} \sim \mathrm{h})$, it can be observed that the corrosion without protective current is very evident: the surface has obvious corrosion products, and the corrosion degree is $73.71 \%$. While under the protection current, the cast iron is slightly corroded, its surface is smooth, and the corrosion degree is $22.10 \%$. This demonstrates that the protection device can greatly improve the corrosion protection of cast iron.

\section{CONCLUSIONS}

In this study, the corrosion behavior of cast iron in different environmental systems was studied with and without protective current, and the influencing factors were analyzed. The results show that during the protection of cast iron, when the cast iron is protected by electricity, in a neutral $(\mathrm{pH}=7)$ environment, the ammonium nitrate concentration is $200 \mathrm{mg} . \mathrm{L}^{-1}$, the sodium chloride concentration is 500 $\mathrm{mg} . \mathrm{L}^{-1}$, or the sodium sulfate concentration is $1000 \mathrm{mg} . \mathrm{L}^{-1}$ and the protection can reach $100 \%$, with the double effect of complete protection and power saving. In this study, a cathodic protection method similar to an applied current is used. That is, a protected metal is used as a cathode, and a piezoelectric anticorrosive sheet acting as an external power source is continuously vibrated to supply electrons to the cast iron sheet so that the cathode is always in an electron excess state. Only the reduction reaction occurs on the surface so that the corrosion of cast iron is suppressed. This pipeline anticorrosion method does not require external chemicals, it has better environmental protection characteristics, and has a demonstrable protective effect on the environment. The PVDF piezoelectric film has a low production cost and is easy to process. When put into use, it plays a protective role

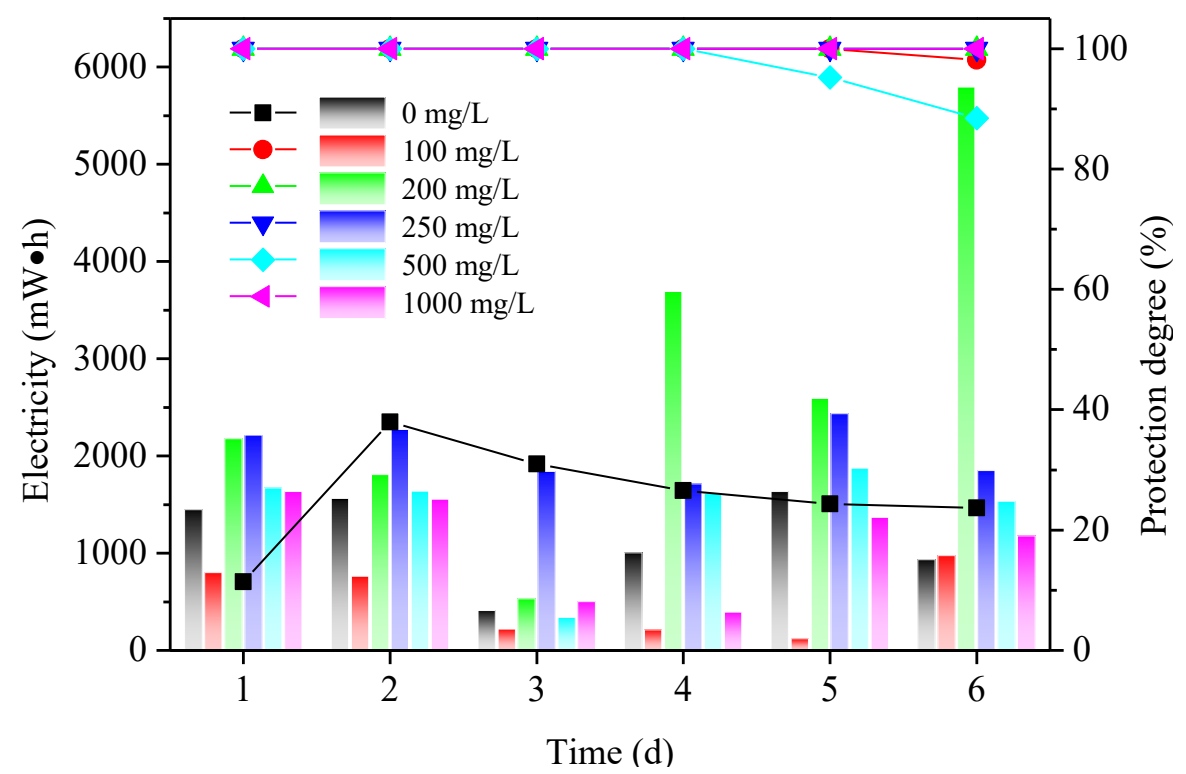

Fig. 12: Under the protection device, the changes in protection degree and power consumption of cast iron under different sodium sulfate concentrations.

Table 3: Cast iron corrosion degree table (data from images at 50 times magnification).

\begin{tabular}{|lllll|}
\hline Solution condition & $\begin{array}{l}\text { Deionized water } \\
\text { no protection }\end{array}$ & $\begin{array}{l}\text { Deionized water } \\
\text { no protection }\end{array}$ & $\begin{array}{l}500 \mathrm{mg} . \mathrm{L}^{-1} \\
\text { no protection }\end{array}$ & $\begin{array}{l}500 \mathrm{mg} . \mathrm{L}^{-1} \\
\text { Protection }\end{array}$ \\
\hline Corrosion degree $(\%)$ & 63.41 & 66.37 & 73.71 & 22.10 \\
\hline
\end{tabular}



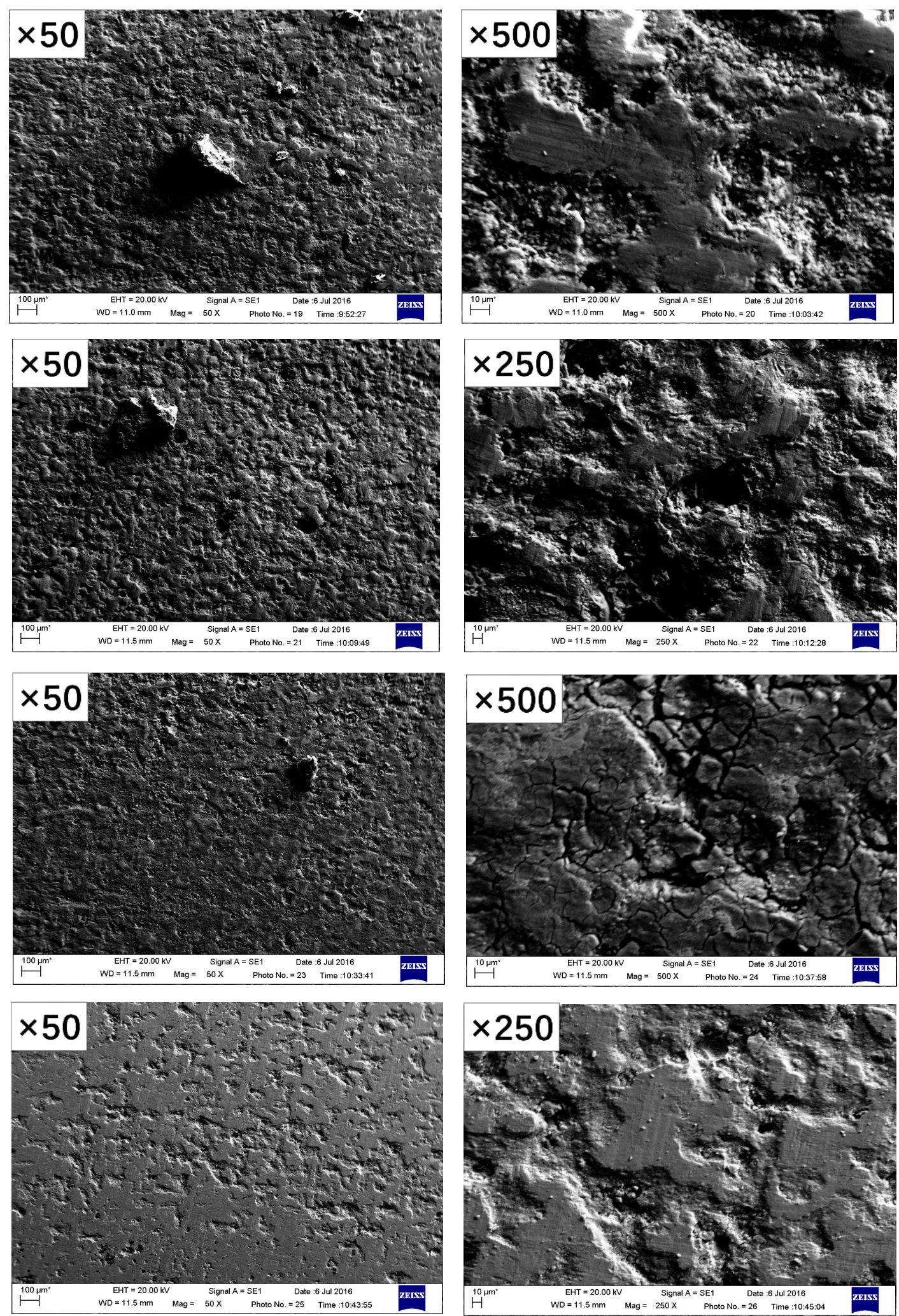

Fig. 13: SEM image of corrosion of cast iron in different concentrations of sodium sulfate solution, at 50, 250, or 500 times magnification. 
on the pipeline, saves the cost of pipeline replacement, and has good economic benefits. The combination of this new material and traditional technology has advantages such as it is environment-friendly, conserves energy, has economic efficiency, and will certainly contribute to China's pipeline anti-corrosion process in the future.

\section{ACKNOWLEDGEMENTS}

This work was financially supported by the Research and Application of Piezoelectric Materials In Soil Remediation (04140007). The author would like to appreciate the support from the Brook Byers Institute for Sustainable Systems, the Hightower Chair, and the Georgia Research Alliance at Georgia Institute of Technology.

\section{REFERENCES}

Butt, Z., Pasha, R.A., Qayyum, F., Anjum, Z., Ahmad, N. and Elahi, H. 2016. Generation of electrical energy using lead zirconate titanate (PZT-5A) piezoelectric material: Analytical, numerical, and experimental verifications. J. Mech. Sci. Technol., 30: 3553-3558.

Chen, B., Li, H., Tian, W. and Zhou, C. 2019. PZT based piezoelectric sensor for structural monitoring. J. Electron. Mater., 1-8.

Dineva, P., Gross, D., Müller, R. and Rangelov, T. (eds) 2014. Dynamic Fracture of Piezoelectric Materials: Solution of Time-Harmonic Problems via BIEM. Springer International Publishing, USA, pp 7-32.

Duan, L. and Xing, J. 2015. Talking about the research status and development trend of piezoelectric materials. Shandong Ind. Technol., 271.

Hu, J., Dong, H., Xu, Q., Ling, W., Qu, J. and Qiang, Z. 2018. Impacts of water quality on the corrosion of cast iron pipes for water distribution and proposed source water switch strategy. Water Res., 129: 428-435.

Joseph, J., Singh, S.G. and Vanjari, S.R.K. 2018. Piezoelectric micromachined ultrasonic transducer using silk piezoelectric thin film. IEEE Electr. Device L.,5: 1-1.

Kim, H.S., Kim, J.H. and Kim, J. 2011. A review of piezoelectric energy harvesting based on vibration. Int. J. Precis. Eng. Man., 12: 1129-1141.

Li, M., Liu, Z., Chen, Y. and Hai, Y. 2016. Characteristics of iron corrosion scales and water-quality variations in drinking water distribution systems of different pipe materials. Water Res., 106: 593-603.

$\mathrm{Li}, \mathrm{Q}$. Research progress in piezoelectric materials used to design filters. In: 2009 Symposium on Piezoelectricity, Acoustic Waves, and Device Applications (SPAWDA 2009), 2009. IEEE, pp 11-11.

Loto, C.A., Loto, R.T. and Popoola, A.P. 2019. Performance evaluation of zinc anodes for cathodic protection of mild steel corrosion in HCL. Chem. Data Collect., 24: 100280.

McNeill, L.S. and Edwards, M. 2002. The importance of temperature in assessing iron pipe corrosion in water distribution systems. Environ. Monit. Assess., 77: 229-242.

Meng, C. and Wang, Y. 2016. The research of the cathodic protection corrosion for transmission station pipeline. Shandong Chem. Ind., 45: 75-77.
Ramatlo, D.A., Wilke, D.N. and Loveday, P.W. 2018. Development of an optimal piezoelectric transducer to excite guided waves in a rail web. NDT. E. Int., 95: 72-81.

Ribeiro, C., Sencadas, V., Ribelles, J.L.G. and Lanceros-Méndez, S. 2010. Influence of processing conditions on polymorphism and nanofiber morphology of electroactive poly(vinylidene fluoride) electrospun membranes. Soft Mater., 8: 274-287.

Sarin, P., Snoeyink, V., Bebee, J., Jim, K., Beckett, M., Kriven, W. and Clement, J. 2004. Iron release from corroded iron pipes in drinking water distribution systems: Effect of dissolved oxygen. Water Res., 38: 1259-1269.

Slaimana, Q.J. and Hasan, B. O. 2010. Study on the corrosion rate of carbon steel pipe under turbulent flow conditions. Can. J. Chem. Eng., 88: 1114-1120.

Sun, H., Shi, B., Lytle, D.A., Bai, Y. and Wang, D. 2014. Formation and release behavior of iron corrosion products under the influence of bacterial communities in a simulated water distribution system. Environ. Sci.: Processes Impacts, 16: 576-585.

Tang, E., Wang, L. and Han, Y. 2019. Space debris positioning based on two-dimensional PVDF piezoelectric film sensor. Adv. Space Res., 63(8): 2410-2421.

Wang, D. and Chen, J. 2016. Progress on the applications of piezoelectric materials in sensors. Mater. Sci. Forum, 848: 749-756.

Wang, R. and Ma, F. 2009. Discussion on corrosion and prevention of urban water supply pipeline. Sci. Technol. Inform., 51: 66-91.

Xu, X., Cao, D., Yang, H. and He, M. 2018. Application of piezoelectric transducer in energy harvesting in the pavement. Int. J. Pavement Res. Technol., 11: 388-395.

Yang, F., Shi, B., Bai, Y., Sun, H., Lytle, D.A. and Wang, D. 2014. Effect of sulfate on the transformation of corrosion scale composition and bacterial community in cast iron water distribution pipes. Water Res., 59: 46-57.

Yang, X., Jiang, H., Song, W., Wang, R., Sun, S. and Jia, R. 2017. Study on the influence of water quality change on iron release in a water supply network of a city and its control effect. J. China Urban Water Assoc., 38-43.

Yang, Y., Tang, H., Gu, L., Wang, H., Zhang, T. and Li, C. 2018. Influence factors of initial internal corrosion of grey cast iron pipes in the water distribution system. China Water \& Wastewater, 34: 49-54.

Zhang, G., Li, B., Liu, J., Luan, M., Yue, L., Jiang, X., Yu, K. and Guan, Y. 2018. The bacterial community significantly promotes cast iron corrosion in reclaimed wastewater distribution systems. Microbiome, 6: 222.

Zhang, L., Yan, C., Rtimi, S. and Bandara, J. 2019. Piezoelectric materials for catalytic/photocatalytic removal of pollutants: Recent advances and outlook. Appl. Catal. B: Environ., 241: 256-269.

Zhang, Y. and Edwards, M. 2007. Anticipating effects of water quality changes on iron corrosion and red water. J. Water Supply Res. Technol.-AQUA, 56: 55-68.

Zhao, Z., Li, J.Q., Yuan, X., Li, X., Zhang, Y. and Sheng, J. 2005. Preparation and properties of electrospun poly (vinylidene fluoride) membranes. J. Appl. Polym. Sci., 97: 466-474.

Zhu, Y., Sun, F., Qian, H., Wang, H., Mu, L. and Zhu, J. 2018. A biomimetic spherical cactus superhydrophobic coating with durable and multiple anti-corrosion effects. Chem. Eng. J., 338: 670-679. 